\title{
Evaluation of the Reinforcing Effects of Monoamine Reuptake Inhibitors Under a Concurrent Schedule of Food and I.V. Drug Delivery in Rhesus Monkeys
}

\author{
Maciej Gasior',3, Jack Bergman', Mary Jeanne Kallman² and Carol A Paronis*,1 \\ 'McLean Hospital, Harvard Medical School, Belmont, MA, USA; '2Eli Lilly and Company, Indianapolis, IN, USA
}

\begin{abstract}
Most medications prescribed for attention-deficit-hyperactivity disorder are psychomotor stimulants with reinforcing effects in laboratory animals (eg methylphenidate). The present studies were conducted to evaluate the reinforcing effects of the recently approved medication atomoxetine in monkeys trained to 'choose' between automated deliveries of either an i.v. injection or food. Rhesus monkeys were trained to lever-press under concurrent schedules of reinforcement; responses on one lever resulted in an injection of either saline or drug, and responses on the alternative lever resulted in food delivery. Data were collected on four measures: response rates, percentage of total responses occurring on the injection-lever (\% ILR), number of injections earned, and number of food pellets earned. Dose-effect functions were determined for cocaine $(0.003-0.3 \mathrm{mg} / \mathrm{kg} / \mathrm{inj})$, methylphenidate $(0.003-0.1 \mathrm{mg} / \mathrm{kg} / \mathrm{inj})$, amphetamine (0.003$0.1 \mathrm{mg} / \mathrm{kg} / \mathrm{inj})$, atomoxetine $(0.01-0.3 \mathrm{mg} / \mathrm{kg} / \mathrm{inj})$, and desipramine $(0.03-1.0 \mathrm{mg} / \mathrm{kg} / \mathrm{inj})$ using a double alternation schedule of saline and drug availability. Results indicate that the distribution of behavior changed according to the drug and dose available for self-injection. Saline availability was typically associated with high rates of food-maintained responding. The \% ILR increased from $3 \pm 1 \%$ when saline was available to $>90 \%$ when $>0.03 \mathrm{mg} / \mathrm{kg} /$ inj of cocaine, methylphenidate or $\mathrm{d}$-amphetamine was available. However, no dose of atomoxetine or desipramine maintained self-administration behavior on the injection-lever. The number of food pellets earned per session decreased as the dose of each drug increased, indicative of behavioral activity with all five drugs. The reinforcing effects of cocaine, methylphenidate, and $d$-amphetamine in these studies are consistent with previous findings in nonhuman primates and with their documented abuse liability. The absence of reinforcing effects of atomoxetine support the view that, like desipramine, it has no evident abuse potential.

Neuropsychopharmacology (2005) 30, 758-764, advance online publication, 3 November 2004; doi: I0.1038/sj.npp. I300593
\end{abstract}

Keywords: abuse liability; atomoxetine; methylphenidate; amphetamine; desipramine; self-administration

\section{INTRODUCTION}

Attention-deficit-hyperactivity disorder (ADHD) is the most common neurobehavioral disorder among children, with an estimated prevalence of 3-7\% in school-aged populations (Goldman et al, 1998; Swanson et al, 1998; American Psychiatric Association, 2000). ADHD is characterized by persistent and developmentally inappropriate levels of inattention, distractibility, impulsivity, and motor activity (American Psychiatric Association, 2000). ADHD

\footnotetext{
*Correspondence: Dr CA Paronis, Preclinical Pharmacology Laboratory, McLean Hospital, I 15 Mill Street, Belmont, MA 02478, USA, Tel: 617855 3330, Fax: 617855 2417, E-mail: cparonis@hms.harvard.edu ${ }^{3}$ Current address: Epilepsy Research Section, NINDS/NIH, I0 Center Drive, MSC: 1408, Building 10, Room 5N250, Bethesda, MD 20892 I408, USA

Received 24 May 2004; revised 10 September 2004; accepted 17 September 2004

Online publication: 22 September 2004 at http://www.acnp.org/citations/ Npp09220404024I/default.pdf
}

also is associated with impairment in academic, occupational, emotional, and social functioning (Biederman, 1998). The disorder may continue into adulthood and be accompanied by considerable comorbidity (Biederman et al, 1991; Goldman et al, 1998; Swanson et al, 1998; Marks et al, 2001).

Drug therapies have proven effective in the management of ADHD, with demonstrated advantages over nonpharmacological interventions such as behavioral and cognitive therapies (Elia et al, 1999; Zametkin and Ernst, 1999). In particular, nearly $90 \%$ of patients with ADHD show clinically significant reductions in symptoms following treatment with psychostimulant drugs such as methylphenidate and $d$-amphetamine (Goldman et al, 1998; Elia et al, 1999). Although not approved for the treatment of ADHD, tricyclic antidepressant drugs such as imipramine and desipramine are used as second-line therapies for ADHD owing to their overall lesser efficacy and adverse side effects. They are typically prescribed only when psychostimulant drugs are ineffective or produce intolerable adverse 
effects (Goldman et al, 1998; Elia et al, 1999). A marked increase in new diagnoses of ADHD has led to a dramatic increase in the prescription of psychostimulant drugs particularly in the US (Goldman et al, 1998). For example, production of methylphenidate has increased several-fold within the last decade and more than $90 \%$ of ADHD patients now receive methylphenidate in the US (Safer et al, 1996; Goldman et al, 1998).

The increased prescription of anti-ADHD medications has been accompanied by increased concern regarding their clinical application. First, both first- and second-line medications produce well-documented adverse effects that may limit their therapeutic benefit (Spencer et al, 2002). Second, the addictive properties of amphetamines and the pharmacological similarity of methylphenidate to abused psychostimulant drugs including cocaine and $d$-amphetamine itself are well recognized (Kollins et al, 2001). Like cocaine, both $d$-amphetamine and methylphenidate produce increases in extracellular dopamine levels and comparable discriminative-stimulus effects in non-human primates and human subjects (Czoty et al, 2004; Kollins et al, 2001; Ritz et al, 1987; Volkow et al, 1999, 2001). Additionally, $d$-amphetamine and methylphenidate maintain i.v. self-administration behavior in several species, suggestive of their abuse liability (for a review, see Kollins et al, 2001). Although there is no consensus whether methylphenidate is widely abused and/or increases the likelihood of substance-use disorders in adulthood (Biederman et al, 1998; Goldman et al, 1998; Sullivan and Rudnik-Levin, 2001; Rush et al, 2001), there have been indications of increases in its diversion and illicit use (see Klein-Scwartz and McGrath, 2003).

The above concerns have led to efforts to develop novel medications and, recently, atomoxetine has been approved for the clinical management of ADHD (Anonymous, 2003). Atomoxetine is reported to be highly effective, yet produce few side effects and be devoid of abuse liability (Heil, 2002; Michelson et al, 2001, 2002; Spencer et al, 1998). Atomoxetine is a selective norepinephrine transporter inhibitor with a relatively low affinity for serotonin and dopamine uptake processes and with minimal affinity for other biological binding sites (Bymaster et al, 2002). Atomoxetine increases dopamine levels in prefrontal cortex, likely mediated by actions at norepinephrine transporters, without increasing dopamine activity in midbrain areas rich in dopamine transporters and associated with the reinforcing effects of drugs, for example, n. accumbens (Bymaster et al, 2002).

The goal of the present study was to compare the relative reinforcing strength of cocaine, atomoxetine, methylphenidate, $d$-amphetamine, and desipramine. The comparison of drugs was made using a novel 'choice' procedure that employs concurrent schedules of i.v. drug self-administration and food delivery in rhesus monkeys (Paronis et al, 2002). This procedure assesses the reinforcing strength of an available dose of drug relative to the reinforcing strength of a food pellet. Results show that the relative reinforcing effects of methylphenidate and $d$-amphetamine were comparable to cocaine, whereas desipramine and atomoxetine did not maintain self-administration behavior, even at unit doses that disrupted food-maintained behavior. The absence of reinforcing effects of desipramine and atomoxetine supports the view that these drugs are devoid of evident abuse potential.

\section{METHODS}

\section{Subjects}

Four female adult rhesus monkeys (Macaca mulatta), weighing $6-7.5 \mathrm{~kg}$, were studied in experimental sessions 5-6 days/week. Subjects were individually housed in stainless steel cages between experimental sessions in a temperature and humidity-controlled room with a 12-h light/dark cycle (0700 hours lights on). Each monkey had unlimited access to tap water and received a nutritionally balanced diet (5045 High Protein Monkey Diet, Purina Mills International, INC., Brentwood, MO) supplemented regularly with fresh fruit, trail mix, and vitamins. All subjects had experimental histories involving psychostimulant drugs.

Monkeys were prepared with chronic venous catheters following the general surgical procedure described by Herd et al (1969). Briefly, under isoflurane anesthesia and in aseptic conditions, one end of a hydrophilically coated polyurethane catheter (inside diameter, $1.0 \mathrm{~mm}$; outside diameter, $1.7 \mathrm{~mm}$ ) was inserted through a femoral vein and passed to the level of the right atrium. The distal end of the catheter was attached to a titanium vascular access port (model TI200 AC-5H; Access Technologies, Skokie, IL) that was subcutaneously located in the midscapular region.

\section{Drugs}

Cocaine $\mathrm{HCl}$ was obtained from the National Institute on Drug Abuse, Rockville, MD. Methylphenidate $\mathrm{HCl}$ and atomoxetine $\mathrm{HCl}$ were a gift from Eli Lilly Company (Indianapolis, IN). $d$-Amphetamine sulfate and desipramine $\mathrm{HCl}$ were obtained from Sigma-Aldrich. Solutions of cocaine, $d$-amphetamine, methylphenidate, and desipramine were prepared in $0.9 \%$ saline. Solutions of atomoxetine were prepared in a $5 \%(\mathrm{w} / \mathrm{v})$ solution of mannitol. Doses of cocaine refer to its free base form; doses of the remaining drugs refer to the their salt forms. Doses are expressed as unit doses $(\mathrm{mg} / \mathrm{kg} / \mathrm{inj})$, that is, the dose available for i.v. injection.

\section{Apparatus}

During experimental sessions, each monkey was seated in a Plexiglas chair within a ventilated, sound-attenuating chamber. Two response levers were mounted on a panel attached to the front of the chair. Each press of either lever with a force of at least $0.25 \mathrm{~N}$ produced an audible click of a relay and was recorded as a response. Red lamps above the levers were illuminated to serve as visual stimuli. A motordriven feeder outside the chamber delivered food pellets to a food receptacle on the chair via flexible tubing connected to a food pellet dispenser (Gerbrands Corp., Arlington MA, Model G530). A motor-driven syringe pump (Med-Associates, Inc., Georgia, VT, Model PHM-100) outside the chamber delivered i.v. injections via an external catheter line to the vascular access port. Each operation of the syringe pump lasted $1.1 \mathrm{~s}$ and delivered a constant volume 
of $0.2 \mathrm{ml}$. Sterile $0.9 \%$ saline $(1-2 \mathrm{ml})$ was used to flush residual drug solution from the port and catheter after each experimental session. All experimental equipment was operated by automatic programming equipment.

\section{Terminal Schedule and Training Sessions}

Each monkey previously had been trained to lever press under a fixed-ratio schedule of food-maintained performance. After food-maintained performance was established on both levers, one lever was randomly designated the food-lever and the alternative lever was the injectionlever. The left lever was the injection-lever for monkeys Mm 211 and Mm 258, and the food-lever for monkeys Mm 259 and $\mathrm{Mm}$ 350. Lever assignments remained constant throughout the present study. Daily experimental sessions were $60 \mathrm{~min}$ and comprised a two-member sequence. In the first member of the sequence, completion of 30 responses (fixed-ratio 30; FR30) on the injection-lever produced a $<3-s$ train of three i.v. injections of the solution available for self-administration followed by a $45-$ $s$ timeout period. Each response on the other lever prior to completion of the fixed-ratio requirement produced a 10-s timeout period. During the second member of the sequence, which lasted for the remainder of the $60-\mathrm{min}$ session, responding was reinforced under concurrent FR30 schedules of i.v. injection and food pellet delivery. Specifically, a single i.v. injection of the solution available for self-administration followed completion of 30 consecutive responses on the injection-lever, whereas delivery of a $1 \mathrm{~g}$ banana-flavored food pellet followed completion of 30 consecutive responses on the second lever (food-lever). A response on one lever reset the response requirement on the opposite lever. Delivery of each reinforcer-food or i.v. injection-was followed by a 45-s timeout period. Stimulus lights of the same color were illuminated above both levers during the first and second members of the schedule except during timeout periods. Responses emitted during timeout periods were recorded but had no scheduled consequences.

Under training conditions, either saline or cocaine $(0.032$ or $0.1 \mathrm{mg} / \mathrm{kg} / \mathrm{inj}$ ) was available for i.v. self-administration. Regardless of daily changes in the availability of saline and unit doses of cocaine, food pellets were always available. Baseline performance for all monkeys was characterized by nearly exclusive responding on the food-lever when saline was available for self-administration, and nearly exclusive responding on the injection-lever when training doses of cocaine were available for self-administration. The availability of saline or cocaine for self-administration changed daily under a double alternation schedule (ie saline-salinecocaine-cocaine-saline-saline) with the proviso that the same unit dose of cocaine was available on two consecutive days (day 1 and day 2). After performance across the different training conditions was stable from day to day, the effects of cocaine and other drugs were studied during test sessions described below.

\section{Test Sessions}

The schedule parameters of test and training sessions were identical, and i.v. self-administration of a full range of unit doses of cocaine and other drugs were studied under the double alternation schedule described above. Unit doses for drugs that maintained i.v. self-administration ranged from doses that did not maintain i.v. self-administration (ie responding was predominantly allocated to the food-lever) up to the doses that maintained i.v. self-administration (ie responding on the food-lever was eliminated by responding on the injection-lever). Drugs were studied in sequence, and experiments with one drug were completed before beginning studies with another drug. Doses of a drug were made available in an irregular order that varied among monkeys. The effects of selected doses of drugs were studied for additional consecutive sessions or redetermined in a second occasion in the event that results obtained for the second consecutive session were not consistent with other data. Periodic sessions with the training doses of cocaine available interposed test sessions with other drugs to ensure maintenance of control performance. Drugs that did not maintain self-administration behavior were studied up to the highest doses that could be studied safely or up to the doses that altered rates or patterns of operant responding under this schedule.

\section{Data Presentation and Analysis}

Number of reinforcer deliveries and responses emitted on each lever were recorded throughout the session. Rate of responding, representing overall behavior on both levers during the concurrent FR schedules (expressed as responses per second), was calculated by dividing the total number of responses on both levers by the total elapsed time (in seconds) excluding responses and time during timeout periods. The percentage of injection-lever responding was calculated by dividing the number of responses emitted on the injection-lever by the total number of responses emitted on the injection-lever and food-lever. Drug intake was calculated by multiplying the number of injections delivered by unit dose.

Data from repeated determinations, including days 1 and 2 of the double alternation schedule, were averaged for individual monkeys. Experimental results are presented as group means $( \pm$ SEM). Potency of self-administered drugs was assessed using linear regression when more than two points were available but were otherwise calculated by interpolation to estimate the unit dose that would result in the allocation of $50 \%$ responding to the injection-lever. Group data also were analyzed by using repeated measures analysis of variance (ANOVA) and Dunnett's test for multiple comparisons of drug vs saline within the same group. A value of $p<0.05$ was used to assess the statistical significance of grouped data.

\section{RESULTS}

\section{Saline and Cocaine Availability}

Cocaine robustly maintained self-administration behavior and produced dose-dependent changes in the distribution of lever-pressing behavior in all monkeys (Figure 1). A twoway repeated measures ANOVA revealed that performance under the concurrent schedules was quantitatively similar 

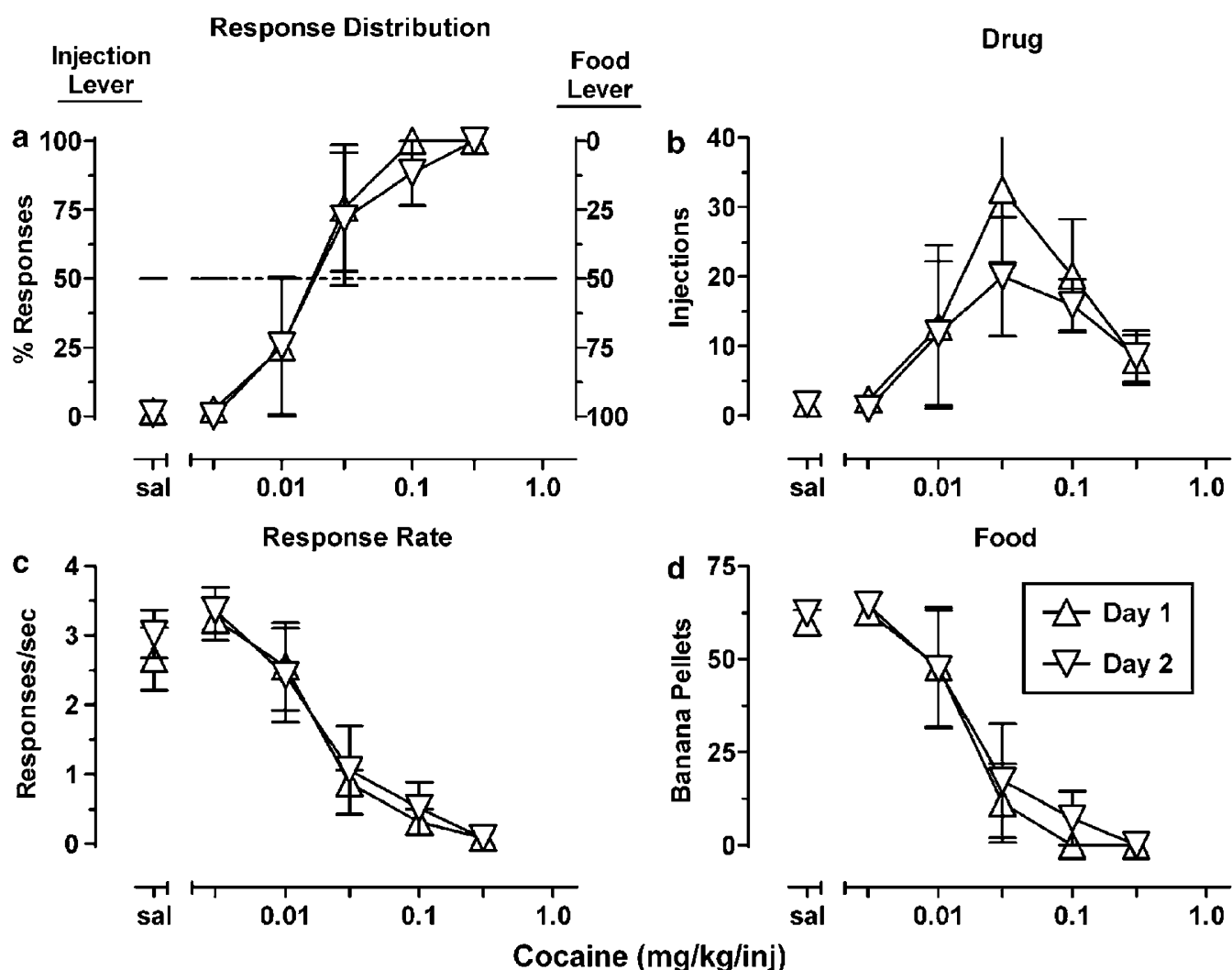

Figure I Distribution of behavior, reinforcers earned, and response rates maintained on consecutive days of availability of saline or different unit doses of cocaine. Abscissae: dose available for i.v. injection; Ordinates: (a) the percentage of responses produced on the injection-lever (left axis) and food-lever (right axis), (b) number of self-administered injections, (c) overall response rates, and (d) number of food pellet deliveries. The dotted horizontal line in (a) represents equal distribution of responding on both levers. Data are expressed as mean \pm SEM of four monkeys at each dose.

on days 1 and 2 of cocaine availability across all unit doses and for all dependent measures collected. Therefore, averaged values of the behavioral measures collected on days 1 and 2 of the double alternation schedule are used to describe effects of cocaine and other drugs hereafter.

When saline was available for i.v. injection, monkeys responded almost exclusively on the food-lever. On average, the percentage of responses on the injection lever was $1 \pm 1 \%$, responding occurred at rates of $2.8 \pm 0.3$ responses/ $\mathrm{s}$, and $61 \pm 2$ food pellets and $1 \pm 1$ i.v. injections were delivered during the 60-min sessions. Quantitatively similar results were obtained with the lowest unit dose of cocaine, $0.0032 \mathrm{mg} / \mathrm{kg} / \mathrm{inj}$. Availability of higher unit doses of cocaine, $0.01-0.32 \mathrm{mg} / \mathrm{kg} / \mathrm{inj}$, resulted in monotonic and dose-dependent increases in the percentage of injectionlever responding and decreases in overall response rates and number of food deliveries. The dose of cocaine calculated to produce $50 \%$ responding on the injectionlever was $0.021 \pm 0.006 \mathrm{mg} / \mathrm{kg} / \mathrm{inj}$. The number of i.v. injections of cocaine increased, then decreased according to unit dose, resulting in a biphasic, inverted U-shaped function. The maximum number of i.v. injections was obtained during the availability of $0.032 \mathrm{mg} / \mathrm{kg} / \mathrm{inj}$ in three monkeys and $0.1 \mathrm{mg} / \mathrm{kg} / \mathrm{inj}$ in one monkey (Mm 259). At the highest unit dose of cocaine, monkeys responded exclusively on the injection-lever with low overall response rates, $0.08 \pm 0.05$ responses/s, resulting in delivery of $8 \pm 4$ injections of cocaine and no food pellets.

\section{$d$-Amphetamine Availability}

$d$-Amphetamine dose-dependently increased the allocation of responding to the injection-lever, with $\geqslant 96 \%$ of responses on the injection-lever during the availability of $0.032 \mathrm{mg} / \mathrm{kg} / \mathrm{inj} d$-amphetamine (Figure 2). As with cocaine, increases in the percentage of injection-lever responding were accompanied by biphasic changes in the number of i.v. injections of $d$-amphetamine and dose-dependent decreases in overall response rates and number of food deliveries (Figure 3). For the group of monkeys, the unit dose of $0.032 \mathrm{mg} / \mathrm{kg} / \mathrm{inj} d$-amphetamine also resulted in the maximal number of i.v. injections of $d$-amphetamine (mean \pm SEM: $24 \pm 10$ ). On average, the unit dose of $d$ amphetamine calculated to produce $50 \%$ responding on the injection-lever was approximately one-half $\log _{10}$ unit lower, or $0.012 \pm 0.003 \mathrm{mg} / \mathrm{kg} / \mathrm{inj}$.

\section{Methylphenidate Availability}

Like $d$-amphetamine and cocaine, methylphenidate robustly maintained self-administration behavior in all monkeys. Methylphenidate was equipotent with $d$-amphetamine in increasing the allocation of behavior to the injection-lever (Figure 2); the unit dose of methylphenidate estimated to produce $50 \%$ responding on the injection-lever was $0.012 \pm 0.006 \mathrm{mg} / \mathrm{kg} / \mathrm{inj}$. Methylphenidate also produced response rate-decreasing effects and decreased the number 


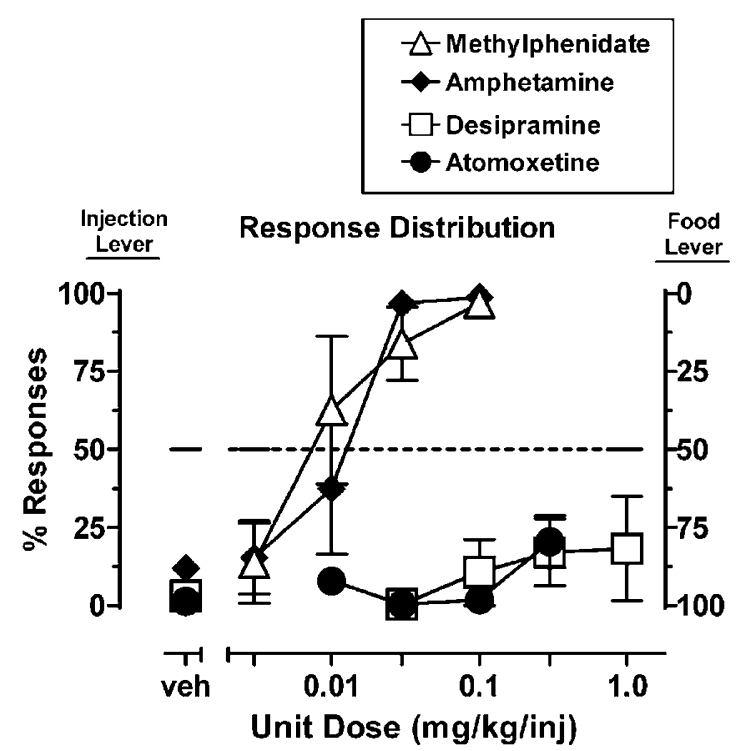

Figure 2 Distribution of behavior during availability of $d$-amphetamine, methylphenidate, desipramine, and atomoxetine. Each data point represents averaged performance on day I and day 2 of the double alternation schedule. Other details as in Figure I.
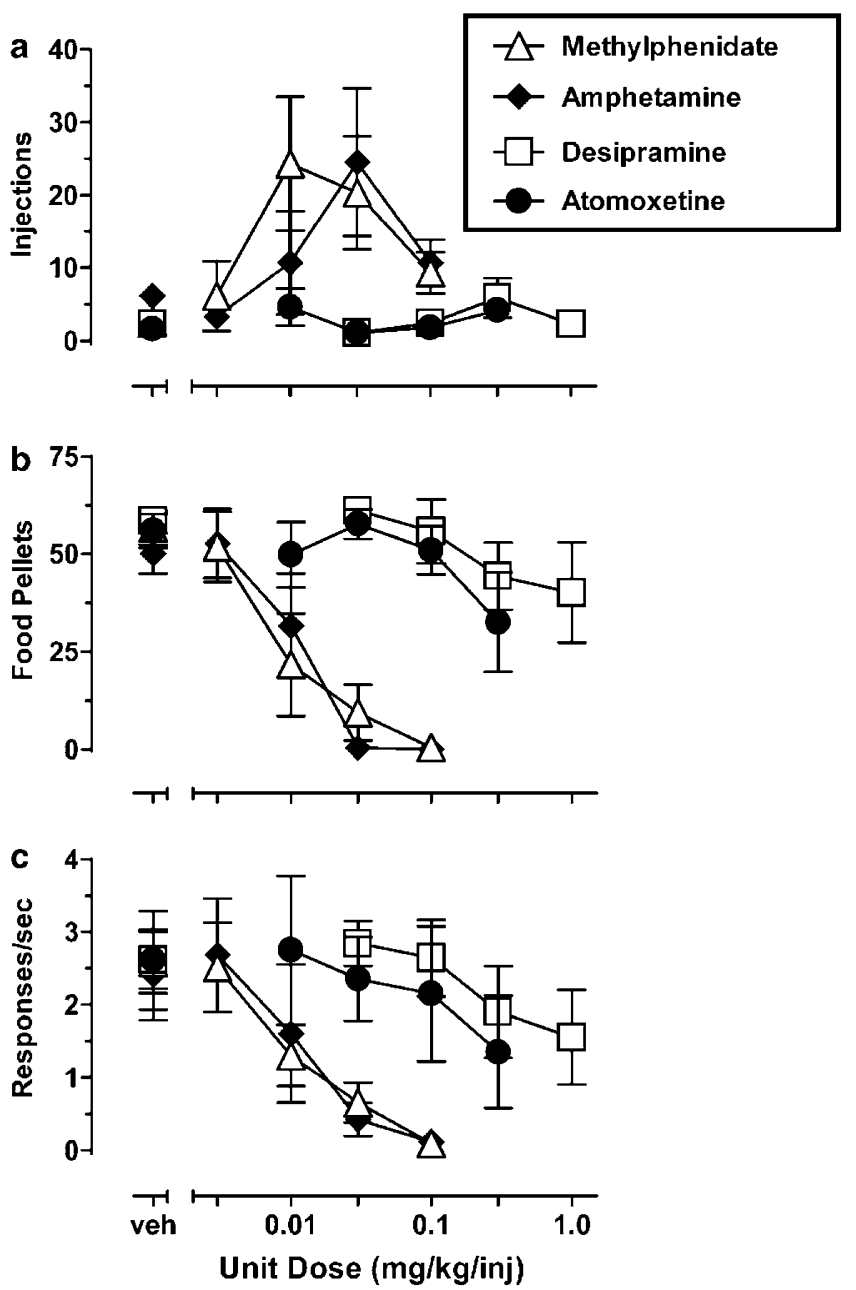

Figure 3 Comparison of (a) the number of self-administered i.v. injections, (b) food pellets earned, and (c) overall response rates during availability of $d$-amphetamine, methylphenidate, desipramine, and atomoxetine. Other details as in Figures $I$ and 2. of food pellet deliveries. The range of unit doses over which these effects were observed was the same as determined for $d$-amphetamine (Figure 3). The biphasic function relating number of i.v. injections to unit dose of methylphenidate shows that the peak number of injections, $23 \pm 9$, was obtained during availability of the unit dose of $0.01 \mathrm{mg} / \mathrm{kg} /$ inj, one-half $\log _{10}$ unit lower than the peak unit dose for $d$-amphetamine in these experiments (Figure 3).

\section{Desipramine Availability}

Desipramine, in contrast to cocaine, $d$-amphetamine, and methylphenidate, did not maintain i.v. self-administration. Food pellet delivery was chosen over i.v. injections across the range of doses of desipramine available for selfadministration, and more than $80 \%$ of all responses were distributed to the food-lever regardless of dose (Figure 2). Accordingly, the number of self-administered injections of desipramine did not increase above values observed during sessions when saline was available for self-administration; the highest number of self-administered injections at any dose was $6 \pm 2$ (Figure 3 ).

Although relatively few injections were delivered, at the highest unit doses of desipramine, 0.3 and $1.0 \mathrm{mg} / \mathrm{kg} / \mathrm{inj}$, average drug intake was, respectively, $2.52 \pm 0.86$ and $4.25 \pm 0.60 \mathrm{mg} / \mathrm{kg}$. This intake, which includes injections received during the sampling component, was sufficient to result in dose-related and statistically significant decreases in overall response rates $\left(\mathrm{F}_{4,12}=6.51, p<0.01\right)$ and number of food pellet deliveries $\left(\mathrm{F}_{4,12}=3.90, p<0.05\right)$. Slight decreases in response rate and food pellet delivery were observed in all monkeys; however, the magnitudes of these effects are mainly attributable to one monkey (Mm 350) that distributed $68 \%$ of responses to the injection lever, resulting in the delivery of three i.v. injections of desipramine.

\section{Atomoxetine Availability}

Like desipramine, atomoxetine did not produce changes in the distribution of lever-pressing behavior and failed to maintain i.v. self-administration (Figure 2). At the highest unit dose tested, $0.32 \mathrm{mg} / \mathrm{kg} / \mathrm{inj},>80 \%$ of responses were allocated to the food-lever. The number of self-administered injections of atomoxetine did not increase above values observed during availability of its i.v. vehicle; on average, the maximal number of i.v. deliveries was $4 \pm 3$. During availability of 0.1 and $0.32 \mathrm{mg} / \mathrm{kg} / \mathrm{inj}$ atomoxetine, total drug intake for the group of monkeys was $0.37 \pm 0.04$ and $1.78 \pm 0.33 \mathrm{mg} / \mathrm{kg}$, respectively.

Although it did not produce substantive increases in injection-lever responding or i.v. injections, atomoxetine decreased overall response rates and the number of food pellet deliveries in a dose-dependent manner. At the highest unit dose of atomoxetine, $0.32 \mathrm{mg} / \mathrm{kg} / \mathrm{inj}$, overall response rates decreased to an average of $52 \%$ of control values (Figure 3). At this dose of atomoxetine, the number of food pellets also was significantly decreased $\left(\mathrm{F}_{4,12}=4.23\right.$, $p<0.05$; Figure 3).

\section{DISCUSSION}

The abuse liability of atomoxetine, desipramine, methylphenidate, $d$-amphetamine, and cocaine were evaluated in 
the present studies by examining the ability of these drugs to maintain self-administration behavior in monkeys allowed to choose between i.v. drug injections and food delivery. The present experiments were conducted in experienced rhesus monkeys that typically respond predominantly on the injection-lever when reinforcing doses of cocaine are available for self-administration and predominantly on the food-lever when vehicle or lesser doses of cocaine are available (Paronis et al, 2002; Gasior et al, 2004). The distribution of behavior under concurrent schedules of food and i.v. drug availability can be taken as a measure of the available drug's relative reinforcing strength, which may reflect its abuse potential. Thus, the allocation of $50 \%$ or less of responding to the injection-lever, indicating that the selfadministered drug's relative reinforcing strength is no greater than that of available food pellets, is suggestive of limited abuse potential, whereas higher levels of responding on the injection-lever are indicative of greater relative reinforcing strength and, likely, greater abuse liability.

Desipramine or atomoxetine resulted in little change in the distribution of behavior ( $<20 \%$ of response allocation to the injection-lever) despite decreases in the number of food deliveries. The range of unit doses available for i.v. selfadminsitration approximate oral doses of desipramine, $2.8 \mathrm{mg} /$ $\mathrm{kg}$, and atomoxetine, $0.5-1.2 \mathrm{mg} / \mathrm{kg}$, recommended for treatment of ADHD (Higgens, 1999; Lynch, 2003) These data indicate that i.v. desipramine and atomoxetine do not have reinforcing properties when food is concurrently available and corroborate earlier reports that desipramine and other tricyclic antidepressant drugs lack abuse potential (Yanagita et al, 1972; Hoffmeister and Goldberg, 1973; Lamb and Griffiths, 1990; Haddad, 1999). In contrast, cocaine, $d$-amphetamine, and methylphenidate all maintained self-administration behavior, indicated by exclusive responding on the injection-lever during the availability of one or more i.v. unit doses in each monkey. The negligible reinforcing strength of atomoxetine and desipramine in the present studies supports the view that they may possess minimal abuse potential.

The similar reinforcing effects of cocaine, methylphenidate, and $d$-amphetamine under concurrent-schedule choice procedures should not be surprising in view of comparable results under single schedules of i.v. drug availability (Balster and Schuster, 1973; Griffiths et al, 1978; Risner and Jones 1976; Bergman et al, 1989). In this regard, double alternation schedules like the one used in the present study previously have been used only in single-lever self-administration studies (Woolverton et al, 2001, 2002). It is noteworthy that functions describing the relation between response allocation and unit dose of drug obtained on the first and second days of the double alternation schedule were comparable and, also, were similar to previously reported effects of these drugs under different choice procedures (Iglauer and Woods, 1974; Paronis et al, 2002; Negus, 2003). The present results extend the conditions under which choice behavior can be evaluated in i.v. selfadministration studies to include double alternation procedures, which may be expeditious for abuse liability evaluation across a full range of unit i.v. doses of a drug.

In summary, the present results are consistent with previous findings suggesting that i.v. $d$-amphetamine or i.v. methylphenidate maintain persistent self-administration behavior in monkeys, predictive of significant abuse- potential for these two drugs (Kollins et al, 2001). The validity of such findings are well established for cocaine and $d$-amphetamine, which have been abused widely in the last 50 years (Foltin and Fischman, 1991). Illicit use and abuse is less well established for methylphenidate, which is prescribed for the treatment of ADHD. The lesser apparent abuse of methylphenidate may be due to several factors, including the ready availability of other psychomotor stimulant drugs, and the relatively tight regulation of the synthesis and supply of methylphenidate to the medical community. Nevertheless, methylphenidate abuse has been reported and the extent to which the prescription and use of methylphenidate also include its misuse and abuse is currently unknown (KleinSchwartz 2002). Illicit use and abuse of atomoxetine, which has only recently been approved for treatment of ADHD has not yet been reported. However, the present results suggest that behaviorally active i.v. doses of atomoxetine display minimal reinforcing strength compared to abused psychostimulant drugs. Based upon this preclinical evaluation, atomoxetine may exhibit low abuse liability, contributing to a favorable therapeutic profile.

\section{ACKNOWLEDGEMENTS}

This study was supported by Eli Lilly and Co and NIH Grants DA11453, DA03774, and DA10566.

\section{REFERENCES}

American Psychiatric Association (2000). Diagnostic and Statistical Manual of Mental Disorders, 4th edn American Psychiatric Association: Washington, DC.

Anonymous (2003). Atomoxetine (Strattera) for ADHD. Med Lett Drugs Ther 45: 11-12.

Balster RL, Schuster CR (1973). A comparison of $d$-amphetamine, $l$-amphetamine, and methamphetamine self-administration in rhesus monkeys. Pharmacol Biochem Behav 1: 67-71.

Bergman J, Madras BK, Johnson SE, Spealman RD (1989). Effects of cocaine and related drugs in nonhuman primates. III. Selfadministration by squirrel monkeys. J Pharmacol Exp Ther 251: 150-155.

Biederman J (1998). Attention-deficit/hyperactivity disorder: a lifespan perspective. J Clin Psychiatry 59(Suppl 7): 4-16.

Biederman J, Newcorn J, Sprich S (1991). Comorbidity of attention deficit hyperactivity disorder with conduct, depressive, anxiety, and other disorders. Am J Psychiatry 148: 564-577.

Biederman J, Wilens TE, Mick E, Faraone SV, Spencer T (1998). Does attention-deficit hyperactivity disorder impact the developmental course of drug and alcohol abuse and dependence? Biol Psychiatry 44: 269-273.

Bymaster FP, Katner JS, Nelson DL, Hemrick-Luecke SK, Threlkeld PG, Heiligenstein JH et al (2002). Atomoxetine increases extracellular levels of norepinephrine and dopamine in prefrontal cortex of rat: a potential mechanism for efficacy in attention deficit/hyperactivity disorder. Neuropsychopharmacology 27: 699-711.

Czoty PW, Makriyannis A, Bergman J (2004). Methamphetamine discrimination and in vivo microdialysis in squirrel monkeys. Psychopharmacology 175: 170-178.

Elia J, Ambrosini PJ, Rapoport JL (1999). Treatment of attentiondeficit-hyperactivity disorder. $N$ Engl J Med 340: 780-788.

Foltin RW, Fischman MW (1991). Assessment of abuse liability of stimulant drugs in humans: a methodological survey. Drug Alcohol Depend 28: 3-48. 
Gasior M, Paronis CA, Bergman J (2004). Modification by dopaminergic drugs of choice behavior under concurrent schedules of intravenous saline and food delivery in monkeys. J Pharmacol Exp Ther 308: 249-259.

Goldman LS, Genel M, Bezman RJ, Slanetz PJ (1998). Diagnosis and treatment of attention-deficit/hyperactivity disorder in children and adolescents. Council on Scientific Affairs, American Medical Association. JAMA 279: 1100-1107.

Griffiths RR, Brady JV, Snell JD (1978). Relationship between anorectic and reinforcing properties of appetite suppressant drugs: implications for assessment of abuse liability. Biol Psychiatry 13: 283-290.

Haddad P (1999). Do antidepressants have any potential to cause addiction? J Psychopharmacol 13: 300-307.

Heil SH, Holmes HW, Bickel WK, Higgins ST, Badger GJ, Laws HF et al (2002). Comparison of the subjective, physiological, and psychomotor effects of atomoxetine and methylphenidate in light drug users. Drug Alcohol Depend 67: 149-156.

Herd JA, Morse WH, Kelleher RT, Jones LG (1969). Arterial hypertension in the squirrel monkey during behavioral experiments. Am J Physio 27: 24-29.

Higgens ES (1999). A comparative analysis of antidepressants and stimulants for the treatment of adults with attention-deficit hyperactivity disorder. J Fam Practice 48: 15-20.

Hoffmeister F, Goldberg SR (1973). A comparison of chlorpromazine, imipramine, morphine and $d$-amphetamine self-administration in cocaine-dependent rhesus monkeys. J Pharmacol Exp Ther 187: 8-14.

Iglauer C, Woods JH (1974). Concurrent performances: reinforcement by different doses of intravenous cocaine in rhesus monkeys. J Exp Anal Behav 22: 179-196.

Klein-Schwartz W (2002). Abuse and toxicity of methylphenidate. Curr Opin Pediatr 14: 219-223.

Klein-Scwartz W, McGrath J (2003). Poison centers' experience with methylphenidte abusein pre-teens and adolescents. J Amer Acad Child Adolesc Psych 42: 288-294.

Kollins SH, MacDonald EK, Rush CR (2001). Assessing the abuse potential of methylphenidate in nonhuman and human subjects: a review. Pharmacol Biochem Behav 68: 611-627.

Lamb RJ, Griffiths RR (1990). Self-administration in baboons and the discriminative stimulus effects in rats of bupropion, nomifensine, diclofensine and imipramine. Psychopharmacology 102: $183-190$.

Lynch T (2003). Atomoxetine for ADHD. Am Fam Physician 68: $1827-1828$.

Marks DJ, Newcorn JH, Halperin JM (2001). Comorbidity in adults with attention-deficit/hyperactivity disorder. Ann NY Acad Sci 931: 216-238.

Michelson D, Allen AJ, Busner J, Casat C, Dunn D, Kratochvil C et al (2002). Once-daily atomoxetine treatment for children and adolescents with attention deficit hyperactivity disorder: a randomized, placebo-controlled study. Am J Psychiatry 159: 1896-1901.

Michelson D, Faries D, Wernicke J, Kelsey D, Kendrick K, Sallee FR et al (2001). Atomoxetine in the treatment of children and adolescents with attention-deficit/hyperactivity disorder: a randomized, placebo-controlled, dose-response study. Pediatrics 108: E83.

Negus SS (2003). Rapid assessment of choice between cocaine and food in rhesus monkeys: effects of environmental manipulations and treatment with $d$-amphetamine and flupenthixol. Neuropsychopharmacology 28: 919-931.

Paronis CA, Gasior M, Bergman J (2002). The effects of cocaine under concurrent fixed ratio schedules of food and i.v. drug availability: a novel choice procedure in monkeys. Psychopharmacology 163: 283-291.

Risner ME, Jones BE (1976). Characteristics of unlimited access to self-administered stimulant infusions in dogs. Biol Psychiatry 11: 625-634.

Ritz MC, Lamb RJ, Goldberg SR, Kuhar MJ (1987). Cocaine receptors on dopamine transporters are related to self-administration of cocaine. Science 237: 1219-1223.

Rush CR, Essman WD, Simpson CA, Baker RW (2001). Reinforcing and subject-rated effects of methylphenidate and $d$-amphetamine in non-drug-abusing humans. J Clin Psychopharmacol 21: 273-286.

Safer DJ, Zito JM, Fine EM (1996). Increased methylphenidate usage for attention deficit disorder in the 1990s. Pediatrics 98: 1084-1088.

Spencer T, Biederman J, Wilens T, Prince J, Hatch M, Jones J et al (1998). Effectiveness and tolerability of tomoxetine in adults with attention deficit hyperactivity disorder. Am J Psychiatry 155: 693-695.

Spencer TJ, Biederman J, Wilens TE, Faraone SV (2002). Novel treatments for attention-deficit/hyperactivity disorder in children. J Clin Psychiatry 63(Suppl 12): 16-22.

Sullivan MA, Rudnik-Levin F (2001). Attention deficit/hyperactivity disorder and substance abuse: diagnostic and therapeutic considerations. Ann NY Acad Sci 931: 251-270.

Swanson JM, Sergeant JA, Taylor E, Sonuga-Barke EJ, Jensen PS, Cantwell DP (1998). Attention-deficit hyperactivity disorder and hyperkinetic disorder. Lancet 351: 429-433.

Volkow ND, Wang GJ, Fowler JS, Fischman M, Foltin R, Abumrad NN et al (1999). Methylphenidate and cocaine have a similar in vivo potency to block dopamine transporters in the human brain. Life Sci 65: L7-12.

Volkow ND, Wang G, Fowler JS, Logan J, Gerasimov M, Maynard L et al (2001). Therapeutic doses of oral methylphenidate significantly increase extracellular dopamine in the human brain. J Neurosci 21: RC121.

Woolverton WL, Hecht GS, Agoston GE, Katz JL, Newman AH (2001). Further studies of the reinforcing effects of benztropine analogs in rhesus monkeys. Psychopharmacology 154: 375-382.

Woolverton WL, Ranaldi R, Wang Z, Ordway GA, Paul IA, Petukhov $\mathrm{P}$ et al (2002). Reinforcing strength of a novel dopamine transporter ligand: pharmacodynamic and pharmacokinetic mechanisms. J Pharmacol Exp Ther 303: 211-217.

Yanagita T, Takahashi S, Oinumia N (1972). Drug dependence liability of tricyclic antidepressants evaluated in monkeys. Jpn J Clin Pharmacol 3: 289-294.

Zametkin AJ, Ernst M (1999). Problems in the management of attention-deficit-hyperactivity disorder. $N$ Engl J Med 340: 40-46. 